\title{
Ectopic testis: an experience of a tertiary- level urology center at Upper Egypt
}

\author{
Rabea Ahmed Gadelkareem ${ }^{1 *}$ (D), Ahmed Abdelhamid Shahat', Ahmed Reda', Ahmed Mohamed Moeen , \\ Mohamed Farouk Abdelhafez', Mahmoud Farouk Abughanima', Osama Mansour², Nasreldin Mohammed ${ }^{1,3}$, \\ Mahmoud Mohammed Osman ${ }^{1}$, Ahmed Abdelaziz Elderwy ${ }^{1}$ and Hisham Mokhtar Hammouda ${ }^{1}$
}

\begin{abstract}
Background: Testicular ectopia is defined as a testis which is located away from the normal pathway of testicular descent and outside its ipsilateral hemiscrotum. Controversies have been raised about considering the abdominal and inguinal ectopic testes as undescended ones. Our purpose was to review our center's experience with the diagnosis and management of testicular ectopia focusing on the inguinal ectopic testis. Retrospectively, we studied the clinical and surgical characteristics of a case series of testicular ectopia which was managed in our center during July 2001-June 2016.

Results: Out of 1132 patients with undescended testes, 44 cases (3.9\%) had testicular ectopia. Twenty-three cases (mean age $=5.15 \pm 5.79$ years) fulfilled the criteria of inguinal ectopic testis. Clinically, testes were relatively mobile and superficial. Surgically, they were located in the superficial inguinal pouch, had relatively long spermatic cords, and commonly had average rather than small sizes. The other ectopic 21 cases (mean age $=10.56 \pm 6.92$ years) were perineal, anterior abdominal wall, femoral, prepubic, and transverse testes in 7 (33.3\%), 4 (19\%), 4 (19\%), 3 $(14.3 \%)$, and $3(14.3 \%)$ cases, respectively. Congenital inguinal hernia was the commonest associated anomaly (22.7\%). All cases were treated surgically with only 1 case of testicular atrophy (2.3\%).

Conclusions: Testicular ectopia is rare with relatively delayed presentations. Different anatomical sites have been reported including the superficial inguinal pouch and anterior abdominal wall with variable complexities and controversies. The inguinal ectopic testis is the most controversial, but it might be characterized from other entities based on certain clinical and surgical criteria.
\end{abstract}

Keywords: Ectopic testis, Inguinal ectopic testis, Perineal testis, Orchiopexy, Transverse testicular ectopia, Undescended testis

\section{Background}

Testicular ectopia is a very rare congenital anomaly of testicular descent. While it represents about $5-10 \%$ of the extrascrotal testicular locations, it has been reported as a cardinal contributor to the differential diagnosis of the clinical term "empty scrotum" [1-3]. It is defined as a testis which is located away from the normal pathway of testicular descent and outside the ipsilateral

\footnotetext{
* Correspondence: dr.rabeagad@yahoo.com

${ }^{1}$ Assiut Urology and Nephrology Hospital, Faculty of Medicine, Assiut University, Elgamaa Street, Assiut 71515, Egypt

Full list of author information is available at the end of the article
}

hemiscrotum. Accordingly, it is different from cryptorchidism or undescended testis which is the arrest of testicular descent at any level along the line of normal descent $[2,4]$. While the majority of cases have been reported as individual case reports, a few case series have been reported so far, either individually for a certain type [2] or collectively for different types [1]. Physical examination plays a fundamental role in the diagnosis of the anomalies of testicular descent, where they have been classified into palpable and impalpable. The majority of cases are palpable (80\%) keeping the indications for imaging or laparoscopy within only $20 \%$ of cases $[3,5-7]$. 
Therefore, full awareness and attentions of the urologists, pediatric surgeons, pediatricians, family doctors, and other primary healthcare physicians are warranted to be vigilant of the anomalies of the male external genitalia and their presentations, regardless to their prevalence $[3,8]$.

Differences between the anomalies of testicular descent are controversial, especially in the case of inguinal ectopic testis [6-10]. Here, we report on our center's experience with the diagnosis and management of ectopic testes with discussion in context of the literature. The question is whether the inguinal ectopic testis could be characterized based on the available clinical and surgical criteria.

\section{Methods}

A retrospective search of the manual and electronic patients' records was done in our center for the operated cases of ectopic testis between July 2001 and June 2016. This study was approved within a project titled "Experience of a Tertiary-Level Urology Center in the Clinical Urological Events of Rare and Very Rare Incidence" by the ethical committee in our university. Clinical characteristics including age; findings of physical examination including the anatomical site, body side, size of ectopic testis, contralateral testis, and other congenital anomalies (if any); investigations; surgical approach and technique; and characteristics on surgical exploration including description of the length of the spermatic cord, location of the testis, and its relation to the external inguinal ring were studied. Testicular size was usually examined relative to the contralateral one. However, assessment of testicular size in comparison to the contralateral one was not feasible in cases with bilateral lesions or a contralateral hydrocele. Moreover, postoperative complications and followup findings were reported.
We differentiated the cases into two groups: inguinal ectopic testes and non-inguinal ectopic testes. According to the literature and guidelines [6-11] and our center's policy, we defined the inguinal ectopic testis as the testis located in the "superficial inguinal pouch" (superior and lateral to the external inguinal ring) which should have its index of suspicion being clinically high and documented during surgery to be differentiated from the "true" undescended, retractile, and ascending testes. When the inguinal testis is fulfilling this definition with a relatively high mobility and getting more prominence on inguinal contraction, it is described as clinically suspicious for testicular ectopia. Surgically, when the testis has confirmed location and gubernacular attachment at the superficial inguinal pouch, a relatively long spermatic cord, and an exit from the external inguinal ring, it is definitively diagnosed as inguinal ectopic testis.

\section{Results}

Between July 2001 and June 2016, 1132 patients were treated by orchiopexy for a congenitally empty scrotum. Of them, 44 cases (3.9\%) had inguinal or non-inguinal testicular ectopia (Tables 1, 2, and 3). Inguinal ectopic testis was the diagnosis in 23 cases which fulfilled the clinical and surgical criteria with 2 cases only were located subcutaneous in the inguinal region (Table 2). The other 21 cases had the distribution between the other ectopic sites including perineal testis in 33.3\% (Fig. 1), abdominal wall (preperitoneal or interstitial) testis in $19 \%$, femoral testis in 19\%, transverse testicular ectopia in $14.3 \%$ (Fig. 2), and prepubic (prepenile or penile) testis in $14.3 \%$ (Table 3 ). In both groups, the age range was $2-11$ and $2-25$ years and the mean age \pm standard deviation was $5.15 \pm 5.79$ and $10.56 \pm 6.92$ years,

Table 1 Collective values and percentages of the common characteristics of the cases in both groups of testicular ectopia

\begin{tabular}{llll}
\hline Parameter $^{\mathrm{a}}$ & Category & Inguinal ectopic testis $(n=23)$ & Non-inguinal ectopic testis $(n=21)$ \\
\hline Subtypes & None & Perineal $(n=7)$ \\
& & Pubopenile $(n=4)$ \\
& & Transverse/contralateral $(n=3)$ & Anterior abdominal wall $(n=4)$ \\
Age (years) & Range & & $2-25$ \\
Anatomical side & Mean \pm SD & $2-11$ & $10.56 \pm 6.92$ \\
& Right & $5.15 \pm 5.79$ & $10(47.6 \%)$ \\
Left & $8(34.8 \%)$ & $10(47.6 \%)$ \\
Testicular size & Bilateral & $14(60.9 \%)$ & $1(4.8 \%)$ \\
Associated anomalies & Average & $1(4.3 \%)$ & $14(66.7 \%)$ \\
& Small & $17(73.9 \%)$ & $7(33.3 \%)$
\end{tabular}

${ }^{a}$ Details of these parameters and other characteristics are presented in Tables 2 and 3 
Table $\mathbf{2}$ Characteristics of the cases of inguinal testicular ectopia

\begin{tabular}{|c|c|c|c|c|c|c|c|c|c|}
\hline \multirow[t]{2}{*}{ No. } & \multirow[t]{2}{*}{ Age } & \multicolumn{5}{|c|}{ Clinical (physical examination) criteria } & \multicolumn{3}{|c|}{ Surgical criteria } \\
\hline & & $\begin{array}{l}\text { Anatomical } \\
\text { side }\end{array}$ & $\begin{array}{l}\text { Relative high } \\
\text { mobility }\end{array}$ & $\begin{array}{l}\text { Prominence } \\
\text { of testis }^{\mathrm{a}}\end{array}$ & $\begin{array}{l}\text { Testicular } \\
\text { size }\end{array}$ & Associated anomalies & $\begin{array}{l}\text { Spermatic } \\
\text { cord }\end{array}$ & $\begin{array}{l}\text { Inguinal } \\
\text { location }^{\mathrm{b}}\end{array}$ & $\begin{array}{l}\text { Relation to } \\
\text { external ring }\end{array}$ \\
\hline 1 & 5 & Left & Positive & Positive & Average & $\begin{array}{l}\text { Left congenital } \\
\text { hernia }\end{array}$ & Long & Superficial & Exited/NA \\
\hline 2 & 6.5 & Right & Positive & Positive & Small & None & Long & Superficial & Exited/cephalad \\
\hline 3 & 2 & Left & Positive & NA & Small & $\begin{array}{l}\text { Left ectopic } \\
\text { kidney }\end{array}$ & Adequate & Superficial & Exited/cephalad \\
\hline 4 & 7 & Left & Positive & Positive & Average & None & Adequate & Superficial & Exited/cephalad \\
\hline 5 & 10 & Left & Positive & Positive & Average & None & Long & Superficial & Exited/cephalad \\
\hline 6 & 3 & Right & Equivocal & Positive & Small & None & Long & Superficial & Exited/cephalad \\
\hline 7 & 3.5 & Left & Equivocal & Positive & Average & $\begin{array}{l}\text { Right congenital } \\
\text { hernia }\end{array}$ & Long & Superficial & Exited/cephalad \\
\hline 8 & 4 & Left & Positive & Positive & Average & Hypospadias & Adequate & Superficial & Exited/NA \\
\hline 9 & 5 & Bilateral & Positive & Positive & Average & None & Adequate & Superficial & Exited/NA \\
\hline 10 & 11 & Left & Positive & NA & Average & None & Long & Superficial & Exited/cephalad \\
\hline 11 & 6 & Left & Positive & NA & Average & $\begin{array}{l}\text { Right congenital } \\
\text { hernia }\end{array}$ & Adequate & Superficial & Exited/cephalad \\
\hline 12 & 8 & Left & Equivocal & Positive & Average & None & Long & Subcutaneous & Exited/cephalad \\
\hline 13 & 2.5 & Left & Positive & NA & Average & None & Long & Superficial & Exited/cephalad \\
\hline 14 & 3.5 & Left & Positive & Positive & Small & None & Adequate & Superficial & Exited/NA \\
\hline 15 & 5 & Right & Positive & Positive & Small & $\begin{array}{l}\text { Left congenital } \\
\text { hydrocele }\end{array}$ & Long & Superficial & Exited/cephalad \\
\hline 16 & 5.5 & Right & Positive & Positive & Average & None & Long & Superficial & Exited/cephalad \\
\hline 17 & 4 & Right & Equivocal & Positive & Small & $\begin{array}{l}\text { Right congenital } \\
\text { hernia }\end{array}$ & Long & Subcutaneous & Exited/cephalad \\
\hline 18 & 5 & Left & Positive & Positive & Average & None & Long & Superficial & Exited/cephalad \\
\hline 19 & 3 & Left & Positive & Positive & Average & $\begin{array}{l}\text { Right congenital } \\
\text { hernia }\end{array}$ & Long & Superficial & Exited/cephalad \\
\hline 20 & 2.5 & Right & Positive & NA & Average & None & Long & Superficial & Exited/cephalad \\
\hline 21 & 4.5 & Right & Positive & Positive & Average & None & Adequate & Superficial & Exited/NA \\
\hline 22 & 9 & Right & Positive & Positive & Average & Right congenital hernia & Adequate & Superficial & Exited/cephalad \\
\hline 23 & 3 & Right & Positive & Positive & Average & None & Long & Superficial & Exited/cephalad \\
\hline
\end{tabular}

NA not available data

aprominence of the testis was considered positive when observing the testis got more prominent while the patient is contracting the abdominal muscles

${ }^{b}$ Superficial means location of the testis in the superficial inguinal pouch (outside the inguinal canal) between the fascial layer and external oblique aponeurosis.

In most of the cases, the gubernacular attachments were reported attached to the boundaries of the pouch or fascial layers

respectively. Only two cases (4.5\%) had bilateral ectopic testes (Tables 1,2, and 3). The presented age was considered as the age of intervention, because all cases were treated within days or weeks from their presentation date to our center.

All cases presented clinically with the complaint of empty scrotum. Regarding the inguinal ectopic testes, they were diagnosed according to the absent history of documented previous scrotal location and the findings of physical examination and surgical exploration (Table 2). To localize the impalpable testes, laparoscopy was done in four cases $(9 \%)$ including three abdominal and one crossed ectopic testes which were initially diagnosed as impalpable testes. The fourth abdominal ectopic testis was treated by open surgery due to unavailability of a laparoscopist at the time of presentation. Imaging including magnetic resonance imaging are not recommended in our policy, but they were requested before presentation to our center (Tables 2 and 3).

In cases of unilateral ectopic testis, the contralateral testis and its adnexa were normal in $34(77.3 \%)$ cases. In the remaining cases, congenital inguinal hernia (15.9\%), cryptorchidism (4.5\%), and congenital hydrocele (4.5\%) were the contralateral associated anomalies. Also, hypospadias (2.3\%) and ectopic kidney (2.3\%) were reported (Tables 1, 2, and 3).

All cases were treated surgically by orchiolysis and orchiopexy, but they were operated by different 
Table 3 Characteristics of the cases of non-inguinal testicular ectopia

\begin{tabular}{|c|c|c|c|c|c|c|c|c|}
\hline No. & Age & Anatomical site/type & Anatomical side & $\begin{array}{l}\text { Testicular } \\
\text { size }\end{array}$ & Associated anomalies & Investigations $^{a}$ & Approach & Complications \\
\hline 1 & 2 & Anterior abdominal wall ${ }^{b}$ & Left & Small & None & Laparoscopy & Laparoscopic & Atrophy \\
\hline 2 & 3.5 & Anterior abdominal wall & Right & Small & $\begin{array}{l}\text { Left inguinal } \\
\text { cryptorchidism }\end{array}$ & Laparoscopy & Laparoscopic & Wound infection \\
\hline 3 & 3 & Anterior abdominal wall & Left & Average & None & MRI & Midline & None \\
\hline 4 & 8.5 & Anterior abdominal wall & Right & Small & None & None & Laparoscopic/inguinal & None \\
\hline 5 & 6.5 & Femoral triangle & Right & Average & None & US & Inguinal/scrotal & None \\
\hline 6 & 7 & Femoral triangle & Left & Average & None & None & Inguinal/scrotal & Hematoma \\
\hline 7 & 15 & Femoral triangle & Left & Small & None & None & Inguinal/scrotal & None \\
\hline 8 & 4 & Femoral triangle & Right & Small & None & US & Inguinal/scrotal & None \\
\hline 9 & 7 & Root of penis & Left & Average & None & None & Inguinal & None \\
\hline 10 & 12 & Root of penis & Left & Average & $\begin{array}{l}\text { Right congenital } \\
\text { hernia }\end{array}$ & None & Inguinal & None \\
\hline 11 & 6 & Penile shaft & Right & Small & None & None & Inguinal/penile & None \\
\hline 12 & 8 & Contralateral hemiscrotum & Right & Average & $\begin{array}{l}\text { Left congenital } \\
\text { hernia }\end{array}$ & US, laparoscopy & Inguinal/scrotal & None \\
\hline 13 & 5 & Contralateral hemiscrotum & Left & Average & $\begin{array}{l}\text { Right congenital } \\
\text { hernia }\end{array}$ & US & Inguinal/scrotal & Hematoma \\
\hline 14 & 25 & Contralateral hemiscrotum & Left & Average & None & US, MRI & Inguinal/scrotal & None \\
\hline 15 & 21 & Perineum & Right & Average & None & None & Inguinal/scrotal & Hematoma \\
\hline 16 & 24 & Perineum & Left & Average & Right cryptorchidism & None & Inguinal/scrotal & None \\
\hline 17 & 17 & Perineum & Right & Average & None & None & Inguinal/scrotal & Hydrocele \\
\hline 18 & 13.5 & Perineum & Right & Average & None & None & Inguinal/scrotal & None \\
\hline 19 & 5 & Perineum & Left & Small & $\begin{array}{l}\text { Right congenital } \\
\text { hydrocele }\end{array}$ & None & Inguinal/scrotal & None \\
\hline 20 & 11 & Perineum & Right & Average & None & None & Inguinal/scrotal & None \\
\hline 21 & 19 & Perineum & Bilateral & Average & None & None & Inguinal/scrotal & None \\
\hline
\end{tabular}

Abbreviations: $M R I$ magnetic resonance imaging, NA not available data, US ultrasonography

${ }^{a}$ Investigations here refer to the non-laboratory workups including imaging and laparoscopy. Imaging were requested before presentation to our center

${ }^{\mathrm{b}}$ Anterior abdominal wall locations were preperitoneal in 3 cases and interstitial in 1 case

surgeons. The preperitoneal testes were located at the inner surface of the umbilical region in two cases and right iliac region in one case without any reported persistent processus vaginalis. Laparoscopic dissection was demanding due to unusual site of the testes, adherence to the underlying tissues, and to preserve them with the relatively small sizes. Inadvertent damage of the testicular blood supply could not be excluded. Owing to this, two-stage Fowler-Stephen operation was carried out in 2 cases. The third preperitoneal case was treated by open orchiolysis and orchiopexy. The interstitial abdominal testis was located at the iliac region between the external oblique and internal oblique aponeuroses without defects in the abdominal wall. On inguinal exploration after laparoscopy which showed a query intracanalicular testis, the spermatic cord was seen exiting the right inguinal ring and traversing upwards and laterally to a small-sized testis underneath the aponeurosis of the external oblique muscle. Regarding the inguinal ectopic testes, the gubernacular attachment was reported to be at the superficial inguinal pouch (in Scarpa's or external oblique fascia) in 18 cases (78.3\%) with failed localization of the layer of fascial attachment in 5 cases (21.7\%). Despite fulfillment of the other clinical and surgical criteria (Table 2), these latter 5 cases were described separately to have an "indeterminate diagnosis of inguinal ectopic testis" due to undefined gubernacular attachments. In the non-inguinal cases, testicular atrophy occurred in 1 case $(4.8 \%)$, while minor complications occurred in 6 cases $(28.6 \%)$ (Table 3). No major complications were reported among the patients of inguinal ectopic testis.

Postoperative follow-up was scheduled at 1 month, 6 months, and every 12 months thereafter. Its duration ranged between 2 and 7 years. Of the 6 patients who were presented above or reached the age of 18 years during follow-up, only two patients were diagnosed with infertility and treated by assisted reproductive techniques. Both of them had unilateral non-inguinal ectopic testes. 

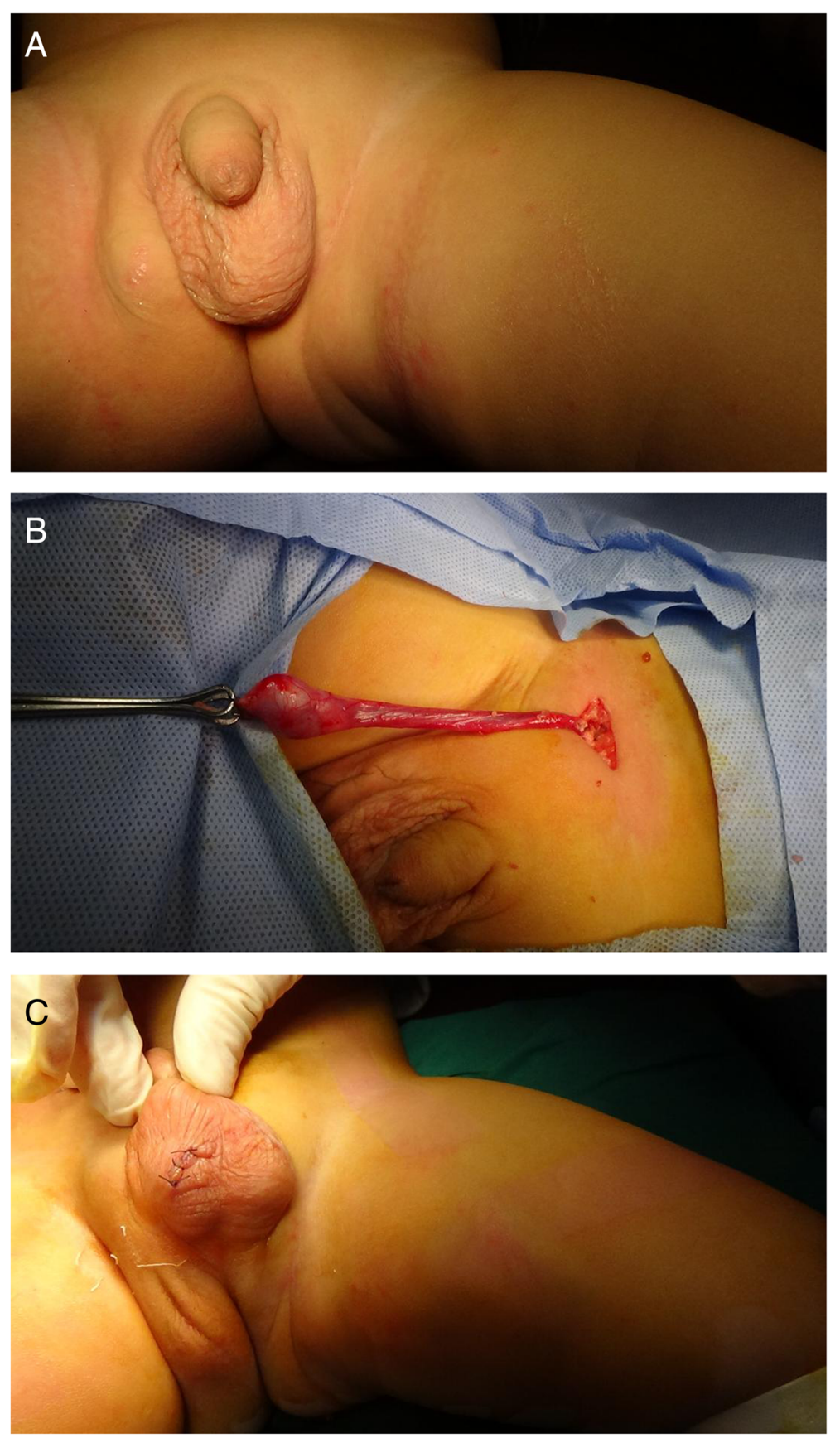

Fig. 1 A 4-year-old boy with right perineal ectopic testis. a A preoperative view showing a well-formed empty right hemiscrotum with a nearby right-sided oval perineal swelling. b An intraoperative view showing the approach via the inguinal skin crease incision, average testicular size, and lengthy spermatic cord. c A direct postoperative view showing the hemiscrotum with the testis repositioned inside. The patient of these pictures is not included in the calculations and numbers in the tables or text, because he presented outside the time frame and after collection of data of this series (in 2019)

\section{Discussion}

The line of testicular descent extends from the level of the lower pole of the kidney to the level of the scrotal neck. Any location of the testis outside this pathway should be classified as testicular ectopia [4, $12,13]$. However, clinically palpable extrascrotal testes should be examined meticulously to differentiate undescended, retractile, ectopic, and ascending testes from each other, with assistance of the other tools of diagnosis, because management could be different $[1$, 2]. The reported positions of ectopic testis include superficial inguinal pouch, perineum, femoral region, 


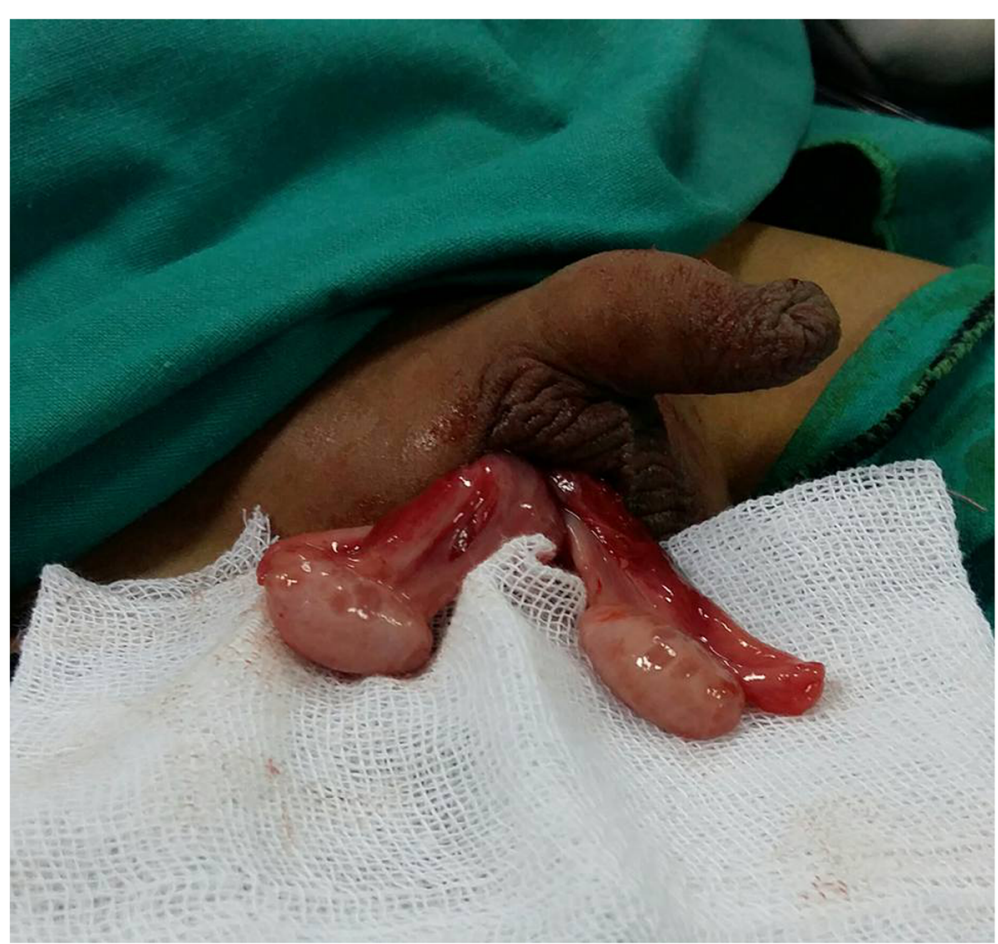

Fig. 2 A 5-year-old boy presented with empty left hemiscrotum due to transverse testicular ectopia which was diagnosed preoperatively by ultrasonography with congenital hernia. A view before scrotal positioning and transseptal orchiopexy. Note the average size of both testes and adequate length of spermatic cords

contralateral hemiscrotum, pubopenile (pubopenile, suprapubic, prepenile, or penile) region, and anterior abdominal wall $[2,3,14]$. However, a new classification should be implemented to withstand all the reported sites of testicular ectopia including the anterior abdominal wall ectopic testes for differentiation from the other entities of abnormal testicular descent $[6,7,15]$.

Age of presentation of testicular ectopia is variable between the neonatal period and adulthood $[13,14,16]$. Abdominal positions of testicular ectopia are extremely rare, where a few cases have been reported so far [4]. Abdominal ectopic testis may be located, either on the inner surface of the anterior abdominal wall to be known as a preperitoneal testicular ectopia [17-19], at the subcutaneous spaces mimicking Spigelian hernia [4, 20], or as interstitial abdominal wall testis which has been recently reported [21]. The preperitoneal positions have been increasingly detectable with the use of laparoscopy which represents the most accurate tool for management of the impalpable and intraabdominal testes [22]. Surgical significances of abdominal ectopic testis may differ from the abdominal undescended testis due to its relatively high and aberrant positions that may render laparoscopic management technically difficult. Preperitoneal locations are exceptions of the well-known definition of ectopic testis, where the testis may not traverse the inguinal canal $[15,18,19]$. Instead, it loops inside the abdominal cavity and resides in unusual sites. Our perspective is to differentiate it from the abdominal undescended testis by its location away from the line of normal testicular descent. Two current cases with preperitoneal position were treated laparoscopically with difficult manipulations that resulted in testicular atrophy in one case. So, the first priority in laparoscopy should go for preservation of the testicular vessels. In cases of inadvertent damage of the testicular blood supply due to unfamiliar position or adhesions to the surroundings, Fowler-Stephen operation could be a valid alternative.

Based on its clinical and surgical criteria, inguinal ectopic testis could be differentiated from cryptorchidic/ undescended, retractile, and ascending testes. Surgically, it is the commonest form of testicular ectopia. The proposed mechanism is that the testis strays the line of descent to the superficial inguinal pouch after exiting the external inguinal ring [8]. Although it could be suspected from the clinical findings, the diagnosis of ectopic inguinal testis could be confirmed only by the findings of surgical exploration similar to the current cases. Controversies have been raised by Murphy and Butler to consider this type just as similar as the inguinal undescended testis depending mainly on its apparent anatomical location in the line of normal descent and a relatively shorter spermatic cord than the other ectopic 
variants $[14,18]$. However, this postulation seems to be inaccurate, if we returned to the definitions and mechanisms of each pathology. So, we prefer to consider the superficial inguinal testis as an ectopic one, when it relocates upwards and laterally from the normal pathway. However, confirmation of the inguinal ectopic testis could be difficult due to failure of localization of the gubernacular inguinal attachments. So, we had to differentiate 5 cases from the current series into a separate group of indeterminate diagnosis of inguinal ectopic testis. However, owing to fulfilling the other criteria including the location away from the line of normal descent clinically and surgically, they were still having higher possibilities of being ectopic inguinal testes rather than any other anomalies of testicular descent.

Length of the spermatic cord of the ectopic testis seems to vary by position. It should be considered as a result rather than a cause of the anomaly, and it is relative to the predefined position by other factors such as the gubernacular attachment. Hence, it is very long for testes that are traversing distantly in certain sites such as the cases of perineal, abdominal wall, and transverse testicular ectopia [14, 20, 23]. However, it is relatively short in the case of the superficial inguinal testis which is located in the nearest site to the external inguinal ring.

The ascending testis is defined as a testis that permanently ascended upwards to the inguinal region after a documented history of previous scrotal location $[9,24]$. It has been suggested that significant proportions of the testes that are treated by orchiopexy are due to ascending testes. The criteria in this definition exclude the possibilities of testicular ascent in our cases. Also, two peaks of orchiopexy have been reported at the ages of 2 and 10-11 years [7, 24], where the second peak has been attributed to the ascending testes. Accordingly, the relative low mean age (5.15 years) of the current series of inguinal ectopic testes could be another difference that they were not ascending testes. On the other hand, missed low lying undescended testes, gliding (pathological retractile testis), and retractile testes have been proposed to contribute to the major proportions of ascending testis rather than the ectopic testes $[7,15,24]$.

Besides the increasingly reported abdominal ectopic testes and the controversial inguinal ectopic ones, other classic types of testicular ectopia are variably reported. Perineal ectopic testis is the commonest form of the non-inguinal testicular ectopia. An observation has been made from the reported cases in the literature and the current series that the perineal testis presents in a relatively older age than the other variants $[13,14,25]$. This finding could be attributed to the anatomical nature of the perineum where it could be missed on physical examination at early presentation. Femoral testis is very rare, located in Scarpa's triangle with its cord is deep to the inguinal ligament, and may mandate a high index of clinical suspicion and demanding surgical dissection. Also, prepubic (prepenile or pubopenile and penile) testes are extremely rare variants $[1,23]$. Transverse testicular ectopia is the most complex form due to several issues that should be considered in management including congenital fusions, difficult differentiation of the testes from each other, and association with other congenital anomalies such as congenital hernia and chromosomal abnormalities such as persistent Mullerian structures. However, introduction of laparoscopy and transseptal orchiopexy techniques has much alleviated these difficulties [1, 23, 26-28].

In contrast to the undescended testis, testicular ectopia has no chances for spontaneous resolution or conservative correction. In a few circumstances, however, complexity of the anomaly such as fusion of the structures with delayed presentation by infertility may prevent surgical correction [16, 26]. Otherwise, surgical correction is recommended as early as possible. Orchiopexy is usually simple due to the long spermatic cord which allows easy repositioning of the testis in the scrotum in most of the variants $[1,2,14]$. However, preperitoneal and transverse testicular ectopia may warrant laparoscopic assistance with technical difficulties $[1,26]$.

Our data showed variable age presentation between childhood and adulthood with more delayed presentations among the non-inguinal ectopic testes relative to the inguinal ectopic testes. Delayed presentation and diagnosis of testicular ectopia may come from different causes including inaccurate physical examination, non-specialized physicians, and lack of awareness of the primary healthcare physicians and families regarding these anomalies. Testicular ectopia has higher potential risks of infertility, malignancy, trauma, and torsion $[1,2,13,27]$. In the current cases, two patients with a unilateral ectopic testis had infertility. Similarly, infertility has been reported with cases of unilateral ectopic testes [13, 14]. Although the post-pubertal ectopic testis may have a fairly normal size, it is prone to have markedly deficient spermatogenesis. This risk could be attributed to loss of the scrotal temperature-regulating effect, delayed presentation, and late orchiopexy. Also, the intrinsic histologic changes could be present owing to the congenital nature $[13,14]$.

\section{Limitations of the study}

Owing to the retrospective nature of the study and different operators of the cases, well-adjusted surgical findings and details were missing in many instances. Accurate description of the testicular size and gubernacular attachment such as to inguinal fascia was deficient in certain cases. Also, analytic and comparative statistical studying was inappropriate. However, retrospective methodology seems to be the most suitable way for these rare entities. 


\section{Conclusions}

Testicular ectopia is very rare with a relatively delayed presentation. Anatomical sites include the superficial inguinal pouch, perineum, femoral region, pubopenile region, contralateral hemiscrotum, and anterior abdominal wall. In spite of the controversies about the inguinal ectopic testes, the clinical and surgical characteristics of these testicles may support advocating the superficial inguinal pouch as a definitive site of testicular ectopia, even to be the commonest site. The inguinal ectopic testis strays the line of normal descent residing upwards and laterally from the inguinal ring. The ectopic testis should be considered with a high index of suspicion on physical examination and during laparoscopy, when the latter is indicated.

\section{Acknowledgements}

Not applicable.

\section{Authors' contributions}

RAG, AAS, AR, and MMO contributed to the study conception and design and manuscript writing. AMM, MFA, MF, NM, and OM contributed to the data acquisition and writing. AAS, MFA, AR, AAE, and MMO contributed to the analysis and data interpretation. RAG, AMM, MFA, MF, OM, and $\mathrm{HMH}$ contributed to the initial drafting of the manuscript. RAG, NM, $A A E$, and $\mathrm{HMH}$ contributed to the critical revision of the manuscript. All authors finally revised and approved the manuscript for submission.

\section{Funding}

This study received no funding from any source.

\section{Availability of data and materials}

All data generated or analyzed during this study are included in this article.

\section{Ethics approval and consent to participate}

This study was approved within the frame of the project "Experience of a Tertiary-Level Urology Center in the Clinical Urological Events of Rare and Very Rare Incidence" by the Ethical Committee of the Faculty of Medicine, Assiut University. Reference approval number is not applicable. Also, it is a retrospective case series study with inclusive written patients' consent to participate in academic research work, where all patients give this written consent on admission in our university hospital with full ethical considerations.

\section{Consent for publication}

Not applicable.

\section{Competing interests}

The authors declare that they have no competing interests.

\section{Author details}

${ }^{1}$ Assiut Urology and Nephrology Hospital, Faculty of Medicine, Assiut University, Elgamaa Street, Assiut 71515, Egypt. ${ }^{2}$ Urology Department, Luxor International Hospital, Luxor, Egypt. ${ }^{3}$ Urology Department, Martin-Luther University, Halle, Germany.

Received: 29 April 2020 Accepted: 13 July 2020

Published online: 17 August 2020

\section{References}

1. Ramareddy RS, Alladi A, Siddappa OS. Ectopic testis in children: experience with seven cases. J Pediatr Surg. 2013;48:538-41. https://doi.org/10.1016/j. jpedsurg.2012.10.005.

2. Celayir A, Sander S, Eliçevik M. Timing of surgery in perineal ectopic testes: analysis of 16 cases. Pediatr Surg Int. 2001;17:167-8. https://doi.org/10.1007/ s003830000468
3. Vieira JF, Brahme G, Pandya N, Desai A. Empty scrotum: undescended testis or ectopic? BMJ Case Rep. 2013;2013:bcr2013009152. https://doi.org/10. 1136/bcr-2013-009152.

4. Haseeb AA, Okasha S, Elbarawy A. Anterior abdominal wall ectopic testes: a report of two cases. Ann Pediatr Surg. 2016;12:25-7. https://doi.org/10.1097/ 01.XPS.0000471672.03400.7c.

5. Mau EE, Leonard MP. Practical approach to evaluating testicular status in infants and children. Can Fam Physician. 2017:63:432-5.

6. Radmayr C, Dogan HS, Hoebeke P, Kocvara R, Nijman R, Stein R, et al. Management of undescended testes: European Association of Urology/ European Society for Paediatric Urology Guidelines. J Pediatr Urol. 2016;12: 335-43. https://doi.org/10.1016/j.jpurol.2016.07.014

7. Elder JS. Surgical management of the undescended testis: recent advances and controversies. Eur J Pediatr Surg. 2016;26:418-26. https://doi.org/10. 1055/s-0036-1592197.

8. Hitzeman N, Usatine R. A boy with undescended testes. West J Med. 2001; 174:238-9. https://doi.org/10.1136/ewjm.174.4.238.

9. Braga LH, Lorenzo AJ, Romao RLP. Canadian Urological Association-Pediatric Urologists of Canada (CUA-PUC) guideline for the diagnosis, management and followup of cryptorchidism. Can Urol Assoc J. 2017;11:E251-E60. https:// doi.org/10.5489/cuaj.4585.

10. Parsons JK, Ferrer F, Docimo SG. The low scrotal approach to the ectopic or ascended testicle: prevalence of a patent processus vaginalis. J Urol. 2003; 169:1832-3. https://doi.org/10.1097/01.ju.0000055606.02062.00.

11. Smith SC, Nguyen HT. Barriers to implementation of guidelines for the diagnosis and management of undescended testis. F1000Research. 2019;8: 326. doi:https://doi.org/10.12688/f1000research.15532.1.

12. Riahinezhad M, Sarrami AH. Absence of canalicular undescended testis during follow-up; where should be examined by ultrasound? J Res Med Sci. 2015;20:320.

13. Maranya G, Mwero B. Perineal ectopic testis in an adult. Ann Afr Surg. 2017; 14:53-4. https://doi.org/10.4314/aas.v14i1.11.

14. Ku J-H, Jeon Y-S, Lee N-K, Kim M-E, Park Y-H. Two cases of perineal ectopic testis. Int J Urol. 2000;7:307-9. https://doi.org/10.1046/j.1442-2042.2000. 00194.x

15. Hack WW, Sijstermans K, van der Voort-Doedens LM, Meijer RW, Haasnoot K The high scrotal ("gliding") testis revised. Eur J Pediatr. 2007;166:57-61. https://doi.org/10.1007/s00431-006-0202-4.

16. Sadeghi-Nejad H, Oates RD. Bilateral crossed testicular ectopia with unilateral absence of the vas deferens: a possible case and hypothetical mechanism. Br J Urol. 1998;81:504-5. https://doi.org/10.1046/j.1464-410x. 1998.00580.x.

17. Raj V, Rajeev R, Joshi S. Abdominal wall ectopic testis - case report and review of literature. J Pediatr Surg Case Rep. 2018;31:26-8. https://doi.org/ 10.1016/j.epsc.2017.12.003

18. Murphy DM, Butler MR. Preperitoneal ectopic testis: a case report. J Pediatr Surg. 1985;20:93-4. https://doi.org/10.1016/s0022-3468(85)80404-8.

19. Yeap MC, Chen JC. Testicular ectopia underneath anterior abdominal wall following fetal peritonitis. Pediatr Neonatol. 2015;56:275-6. https://doi.org/ 10.1016/j.pedneo.2014.10.008

20. Pandey A, Rawat J, Pandey J, Singh S, Gopal SC. Abdominal wall ectopic testis mimicking Spigelian hernia. J Pediatr Surg. 2011;46:415-6. https://doi. org/10.1016/j.jpedsurg.2010.09.102.

21. Natarajan M, Alnajjar HM, Woodward Cl, Tshuma M, Marshall T, Rochester M Abdominal wall ectopic testis torsion mimicking a Spigelian hernia in an adult. Ann R Coll Surg Engl. 2017;99:e65-8. https://doi.org/10.1308/rcsann. 2016.0335.

22. Budianto IR, Tan HL, Kinoshita Y, Tamba RP, Leiri S, Taguchi T. Role of laparoscopy and ultrasound in the management of "impalpable testis" in children. Asian J Surg. 2014;37:200-4. https://doi.org/10.1016/j.asjsur.2014.01.013.

23. Pugach $J \mathrm{~L}$, Steinhardt GF. Evaluation and management of ectopic penile testis. Urology. 2002:59:137vii-137viii. https://doi.org/10.1016/s00904295(01)01473-x.

24. Agarwal PK, Diaz M, Elder JS. Retractile testis - is it really a normal variant? J Urol. 2006;175:1496-9. https://doi.org/10.1016/S0022-5347(05)00674-9.

25. Raj V, Redkar RG, Krishna S, Tewari S. Rare case of transverse testicular ectopia - case report and review of literature. Int J Surg Case Rep. 2017;41: 407-10. https://doi.org/10.1016/j.ijscr.2017.09.032.

26. Yanaral F, Yildirim ME. Testicular fusion in a patient with crossed testicular ectopia: a rare entity. Urol Int. 2013·90:123-124. https://doi.org/https:/doi. org/10.1159/000343685. 
27. Abdelmalak M, Waheeb S, Koraitim A, Mahdy D, ElMigeid DMA. Two cases of transverse testicular ectopia in consanguineous boys. Eur J Pediatr Surg Rep. 2018;6:e90-3. https://doi.org/10.1055/s-00381667329.

28. Ulubay M. Perineal ectopic testis: a rare congenital anomaly. Urol Case Rep. 2019;24:100853. https://doi.org/10.1016/j.eucr.2019.100853.

\section{Publisher's Note}

Springer Nature remains neutral with regard to jurisdictional claims in published maps and institutional affiliations.

\section{Submit your manuscript to a SpringerOpen ${ }^{\circ}$ journal and benefit from:}

- Convenient online submission

- Rigorous peer review

- Open access: articles freely available online

- High visibility within the field

- Retaining the copyright to your article

Submit your next manuscript at $\boldsymbol{\sim}$ springeropen.com 